\title{
CARDENOLIDES OF Adonis wolgensis
}

N. F. Komissarenko, É. P. Korzennikova,

UDC $547.92+615.711 .5$ and V.Ya. Yatsyuk

It is known that the herb Adonis wolgensis Steven possesses a cardiotonic activity [1]. However, there have been no investigations to determine the structure of the active substances.

We give the results of a study of the cardiotonic substances of $A$. wolgensis.

By chromatography on paper of purified extracts of the epigeal part of the plant in the benzenemethyl ethyl ketone $(95: 5)$ /water (35\%), chloroform/formamide $(25 \%)$, and tetrahydrofuran-chloroform $(1: 1)$ /formamide $(25 \%)$ systems, no less than 10 substances of cardenolide nature were detected. The extraction, purification, and separation of the substances was performed as described previously [2].

Three cardenolides were obtained which were shown by their physicochemical properties, transformation reactions, colorations with $84 \%$ sulfuric acid, $\mathbf{R}_{f}$ values in various systems, IR spectra, and mixed melting points to be identical with the following substances obtained previously from A. amurensis [2]:

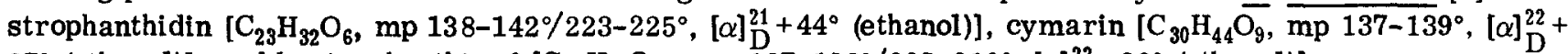
$37^{\circ}$ (ethanol)], and k-strophanthin- $\beta\left[\mathrm{C}_{36} \mathrm{H}_{54} \mathrm{O}_{14}, \mathrm{mp} 187-193^{\circ} / 205-210^{\circ},[\alpha]_{\mathrm{D}}^{22}+32^{\circ}\right.$ (ethanol)].

\section{LITERATURE CITED}

1. I. G. Zoz, N. F. Komissarenko, and N. A. Chernykh, Rast. Res., 3, No. 2, 276 (1967).

2. A. A. Ponomarenko, N. F. Komissarenko, and K. L. Stukkei, Khim. Pri rodn. Soedin., 848 (1971).

Khar'kov Chemical and Pharmaceutical Scientific-Research Institute. Translated from Khimiya Prirodnykh Soedinenii, No. 3, pp. 433-434, May -June, 1973. Original article submitted December 21, 1972.

() 1975 Plemum Publishing Corponation, 227 West 17th Street, New York, N.Y. 10011. No part of this publication may be reproduced, stored in a retrieval system, or transmitted, in any form or by any means, electronic, mechanical, photocopying, microfilming, recording or otherwise, without written permission of the publisher. A copy of this article is available from the publisher for $\$ 15.00$. 